\title{
THE STRUCTURE AND RELATIONSHIPS OF OLIARCES (NEUROPTERA) ${ }^{1}$
}

\author{
By Frank M. Carpenter \\ Harvard University
}

Somewhat more than forty years ago, Dr. John B. Smith, while traveling in California, collected a conspicuous neuropterous insect, which was subsequently described by Banks (1908) as Oliarces clara. Efforts to find additional individuals were unsuccessful for many years, but a second specimen has at last been secured. Mr. P. A. Adams, of the University of California, who received the insect from the collector and who has already published a note on its discovery (1950), kindly loaned me the new specimen for further study and for comparison with the type. I am indebted to him for this courtesy and for the opportunity of clarifying, to some extent, the systematic position of this remarkable insect.

The type locality, "Walters Sta., Calif.", has been the subject of much speculation and its location not generally known. According to Mr. Banks (personal communication) Smith collected the specimen while the train on which he was traveling was stopped at Walters Station for water. Current maps do not include this place, but the 1901 edition of the Century Atlas shows a "Walters" on the Southern Pacific Railroad, about ten miles northwest of the Salton Sea bed; and the engineering department of the Southern Pacific Company informs me that this was a station around 1900. It is also listed in Gannett's "Dictionary of Altitudes" (1906), which further states that the "point on base under water tank" is 191 feet below sea level. There is no doubt in my mind, therefore, that this Walters is the type locality of clara. The new specimen was collected near Parker Dam, San Bernardino County, about 70 miles from Walters and in the same kind of environment.

${ }^{1}$ Published with the aid of a grant from the Museum of Comparative Zoology at Harvard College. 
The following account of the structure of Oliarces clara is based on the holotype (male) and the new specimen (female), which is here designated the allotype:

Frons and vertex dark brown to black; clypeus, mouthparts and antennae light reddish brown; pronotum and mesonotum dark brown to black; metanotum dark reddish brown, lighter near wing bases; legs yellow-gray to medium brown; abdominal tergites medium brown, membranous areas yellow-brown; last two abdominal segments dark reddish brown above; abdomen yellow from beneath. Wings hyaline, the bases tinted with reddish brown. Antennae (broken away at second segment in holotype) with 40 subequal segments. Body in general covered with long brown or black hairs. Fore wing of holotype $16 \mathrm{~mm}$. long and $5 \mathrm{~mm}$. wide (maximum) ; that of allotype $20 \mathrm{~mm}$. long and $7 \mathrm{~mm}$. wide. Both pairs of wings are of similar texture, being colorless and hyaline. Each wing bears two distinct nygmata. The wing venation of the allotype is shown in text-figure 2 ; that of the holotype has already been figured by Banks (1908). As Adams has pointed out, the venational differences in the wings of the two specimens are well within the limits of variation occurring in other Neuroptera. A discussion of the generic features of the venation is included below.

The terminal abdominal segments of the male, briefly described by Banks, are illustrated here (Plate 4, fig. 2) in detail because of their significance in determining generic relationships. The ninth tergite is much longer laterally than dorsally, being reduced to a narrow strip in the middorsal region. The ninth sternite has migrated posteriorly so that it is ventral to the tenth tergite; it is long laterally but constricted medially. The tenth tergite is conspicuously extended to form the anal plates, which are directed more dorsally than ventrally and which appear from above like hairy knobs. A posterior-dorsal view of the abdomen clearly shows the anus, as well as a pair of sclerotized structures which are apparently the modified tenth sternite.

The terminal segments of the female abdomen are shown in figure $3 \mathrm{~B}$, drawn from Mr. Adams' specimen. Although 
these were not removed and softened, as was done with the holotype, the sclerites are clearly defined. The eighth tergite extends further ventrally than the preceding tergites, and the ninth extends to the ventral surface. The eighth sternite is not visible externally, but is presumably reduced to sclerotized rods or plates encompassed by the ninth tergite. The tenth tergite is small and tapering, with conspicuous trichobothria near the margin of the ninth tergite. The ninth sternite is represented by a pair of very small plates, more or less fused, each bearing a minute papilla distally. These two plates are apparently the homologues of the psammarotrum or sand-plow of the Australian ithonids.

Holotype ( 1 ) : Walters Station, California; April (J. B. Smith); in M.C.Z.

Allotype (by present designation) : $3 \mathrm{mi}$. southwest of Parker Dam, San Bernardino Co., April 25, 1949 (C. M. MacNeill), taken at light; in collection of P. A. Adams.

Since only one species of Oliarces is known, any diagnosis of the genus is probably tentative. However, considering the characteristics involved in the classification of other Neuroptera, I propose the following: the hyaline nature of both pairs of wings; in the fore wing the presence of a recurrent costal vein, of about five (probably variable) branches of Rs, and of relatively few cross-veins in the wing as a whole, as well as the absence of connecting cross-veins between costal veinlets; in the hind wing the transverse position of the basal part of MA (see below); in the male abdomen, the dorsally directed anal plates; and in the female, the absence of a distinct psammarotrum. The presence of two nygmata in the hind wing is of doubtful generic value, although only one is present in the specimens which I have seen of Ithone, Heterithone and Varnia.

The relationships of Oliarces with other Neuroptera have been very uncertain. Although originally placed by Banks $(1908,1913)$ in the family Hemerobiidae, as broadly conceived, it does not fit into the current and more restricted definition of that family. Tillyard, who noted this in 1916, suggested that a new family might be needed for it, but did not formally establish one. On the other hand, Brues and 
Melander (1932) listed the genus under the family Ithonidae, otherwise known only from Australia; and Lameere (1936) has placed it in the Polystoechotidae. Since the uncertainty of the systematic position of Oliarces has been due in part to our very limited knowledge of the species on which it was based, the discovery of the female has given us additional information useful in comparisons.

It is at once clear, of course, that several superfamilies (Tillyard, 1925) of the Neuroptera--specifically the Coniopterygoidea, Nemopteroidea and Myrmeleontoidea - are so far removed structurally from Oliarces as to be eliminated from further consideration. The superfamily Hemerobioidea is not so readily disposed of, but many of the included families (i.e., Dilaridae and Mantispidae) can have only the remotest affinities with Oliarces. The Osmylidae, although superficially resembling Oliarces more than most hemerobioids, have a radically different abdominal structure, as can be seen by comparing Killington's figures of Osmylus (1936, p. 56 and 58) with those of Oliarces in the present paper. The Polystoechotidae, to which Lameere assigned Oliarces, and which were reviewed in my 1940 revision, have wings with definite gradate veins, absent in Oliarces; and the terminal abdominal segments (Carpenter, 1940, figs. 70 and 72) of both sexes bear no resemblance to those of Oliarces, there being no anal plates in the male and no indication of a psammarotrum in the female. The Hemerobiidae, being a much larger and diversified family than the Osmylidae and Polystoechotidae, exhibit a greater range of structural differences (Killington, 1936-37; Carpenter, 1940 ). In all, however, there are gradate veins and a venational pattern basically unlike that of Oliarces. The terminal abdominal segments of the males of some genera are surprisingly suggestive of those of Oliarces, but this is not true of the females.

I have passed over these hemerobioid families very briefly because I believe that anyone who examines the specimens of Oliarces or studies the figures included here will not seriously consider assigning the genus to any of them. The family Ithonidae, however, deserves much more detailed 
consideration. As now known, it consists of three Australian genera: Ithone (New South Wales) with one species; Heterithone (eastern Australia) with three species; and Varnia (central and Western Australia) with a single species. ${ }^{2}$ Ithone is the only one of these that has been collected in large numbers, the others being known by very few individuals. Specimens of all of these genera are contained in the Museum of Comparative Zoology, and have been studied for the present paper. Since no detailed drawings have been published showing the arrangement of the terminal ab-
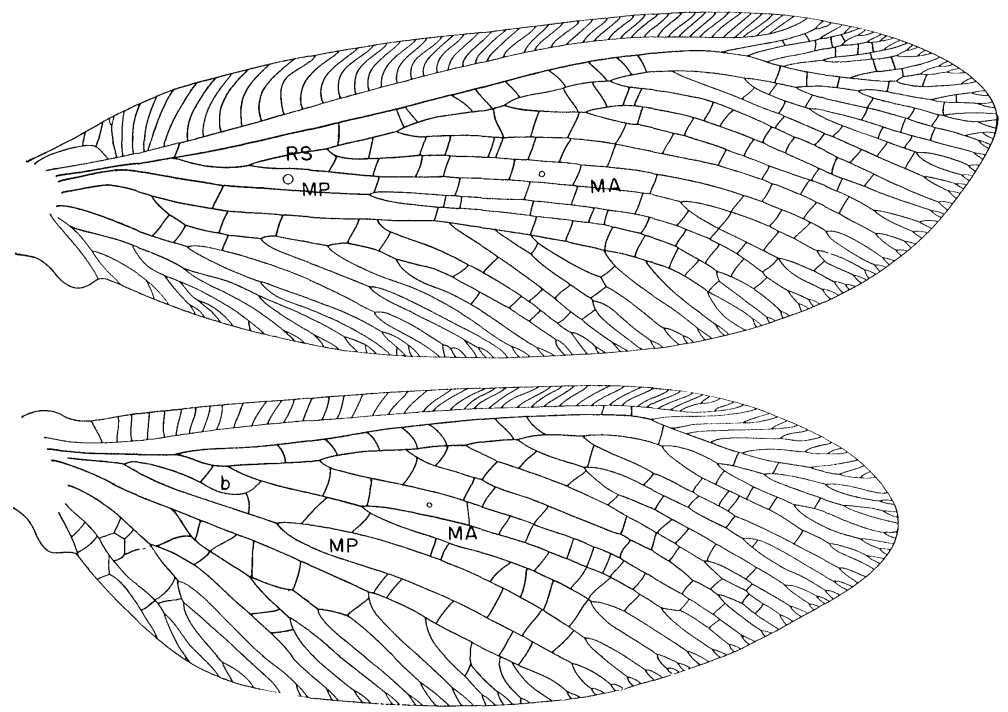

Text-fig. 1. Ithone fusca Newman. Fore and hind wings of male specimen in M. C. Z. (Woy Woy, N. S. W., Nov. 4, 1918, R. J. T.). Rs, radia! sector; MA, anterior media; MP, posterior media; b, basal piece of MA between MP and Rs.

dominal sclerites in the Ithonidae, I include here a series of such drawings of Ithone fusca, and, to facilitate comparison with Oliarces, a drawing of the wings of the same species.

2 The monotypic genus Rapisma, from the Malay Peninsula, has been doubtfully referred to the Ithonidae by some workers, but was excluded from there by Tillyard (1916). It will be treated in another article. 
In comparing the venation of these genera with that of Oliarces, I have found it helpful to use the interpretation of neuropterous venation that was originally proposed by Martynov and that I employed in my revision of the Nearctic Hemerobioidea (1940, pp. 193-194). According to this concept, the most anterior branch of the media (labeled MA) is anastomosed in part with the radial sector or its last branch. In the fore wing, the actual separation of MA from
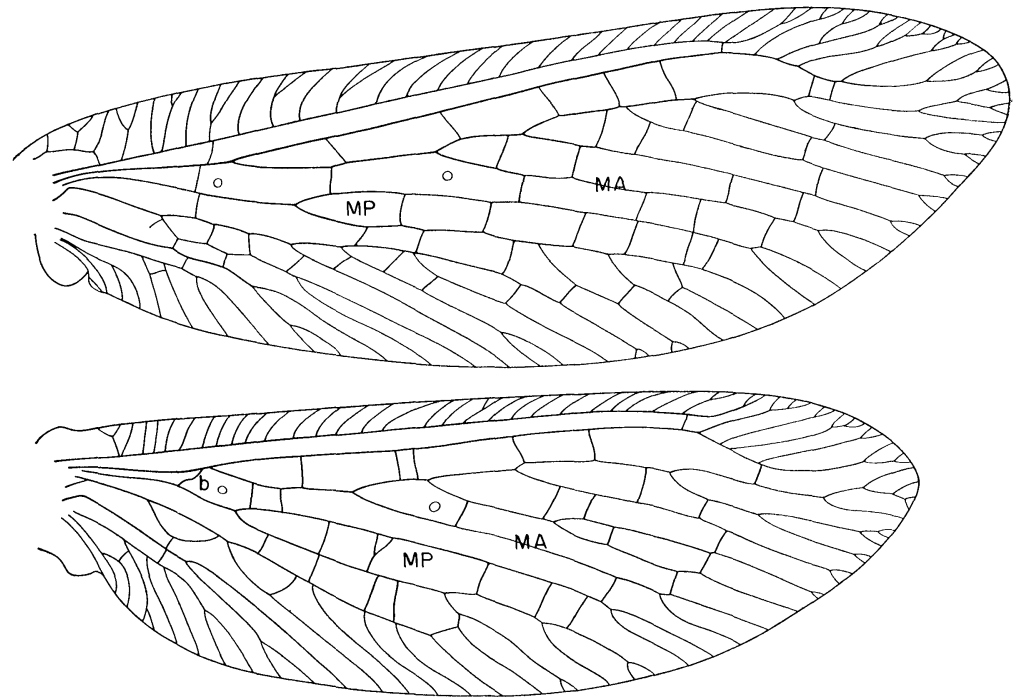

Text-fig. 2. Oliarces clara Banks. Fore and hind wings of allotype. Lettering as in text-figure 1.

MP is not apparent, but in the hind wing the basal piece of MA may extend a considerable distance before coalescing with the radial sector. Such is the case in Ithone (textfigure 1), Heterithone and Varnia. In Oliarces this segment of MA is very short and transverse, though it retains the sigmoidal form present in the Australian ithonids. This difference should not be regarded as more than of generic significance, however, since the several genera of Hemerobiidae exhibit a comparable diversity in the length of this segment. The same may also be said of the density of the 
venation, for although there are fully twice as many terminal branches in the ithonids as in Oliarces, such diversity likewise occurs within the Hemerobiidae.

The general body structure of Oliarces, including the small, retracted head, and the large abdomen, strongly resembles that of the ithonids. The terminal abdominal segments, however, present some interesting differences. In the male of Ithone, as well as of Heterithone and Varnia, the ninth abdominal tergite is entire dorsally, even though much constricted (Plate 4, fig. 1A). The ninth sternite (hypandrium of Tillyard's terminology) of these genera, as in nearly all Planipennia, is extended further posteriorly than the tergite, but it is not nearly so modified here as in most Neuroptera. The tenth tergite, which includes the trichobothria, bears a pair of conspicuous anal plates, extending posteriorly and slightly curved inwardly. The tenth sternite is apparently reduced to internal plates, as in nearly all other Neuroptera. The homologues of the sclerites are
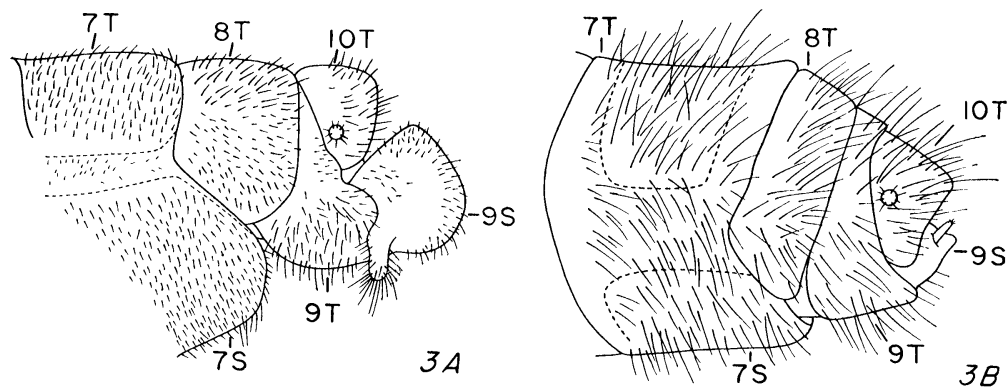

Text-fig. 3. A, Terminal abdominal segments of female of Ithone fusca Newman. Drawn from specimen in M. C. Z. (Woy Woy, N. S. W., Nov. 3, 1918, R. J. T.). Lettering as in text-figure 1. B, Terminal abdominal segments of female of Oliarces clara Banks. Drawn from allotype. Lettering as in text-figure 1.

readily found in Oliarces. Its ninth tergite is more constricted medially than in Ithone, but it is still undivided. The ninth sternite has migrated further posteriorly, and is smaller than in Ithone, but is otherwise similar. The anal plates of the tenth tergite, though directed upwards instead 
of posteriorly, could easily be modifications of those of Ithone.

The terminal abdominal segments of the female of Ithone are shown in text-figure 3A. Tillyard, in describing these $(1919$, p. 426), states that the eighth, ninth and tenth abdominal segments "are more or less fused together, forming the projecting end of the abdomen." In alcoholic specimens, however, the segments are perfectly distinct. The eighth tergite extends further ventrally than the seventh; and the ninth, as in nearly all Planipennia, reaches all the way to the ventral surface. The eighth sternite is not visible externally. The ninth sternite in all the ithonids is posterior to the ninth tergite and is enlarged to form the sand-plow or psammarotrum. Its two lateral plates are fused dorsally by membranes but are, of course, separated posteriorly in the region of the gonopore. The psammarotrum bears a pair of conspicuous processes, directed ventrally; these were thought by Tillyard to be used as tactile organs during oviposition. The tenth tergite is short, hood-shaped and bears the trichobothria. In Oliarces (Figure 3B) the ninth tergite is not so long ventrally as in Ithone and the ninth sternite is reduced to a pair of very small plates, scarcely extending beyond the tenth tergite. That these plates do comprise the ninth sternite is indicated by the presence of a pair of small distal papillae, which, although they project dorsally, are clearly homologues of the longer, ventral processes in Ithone. No true psammarotrum, comparable to that of Ithone, is formed, but the structure is there in reduced form. The tenth tergite of Oliarces is similar to that of Ithone, except for a slight difference in its shape.

From the evidence reviewed above, Oliarces appears to be closer to the Australian ithonids than to any other Neuroptera. This resemblance is, in fact, so close that only one modification need be made of Tillyard's definition of the family; this is the recognition that the psammarotrum may be very small or vestigial. ${ }^{3}$ It is noteworthy in this con-

\footnotetext{
${ }^{3}$ Tillyard also stated in his definition of the Ithonidae that the fore wings were of tougher consistency than the hind, being somewhat leathery; but this is certainly not true of Heterithone pallida, which Tillyard himself described as having very transparent and colorless wings.
} 
nection that the reduced psammarotrum in Oliarces and many of its other features (e.g., the short basal piece of MA in the hind wing) appear specialized as compared with the corresponding structures of the Australian ithonids. The inclusion of Oliarces in the Ithonidae certainly makes an unusual distributional pattern for the family, but the paucity of specimens of most species implies that the group might well have a much wider distribution than is now known. Of course, since the larvae of the Neuroptera provide the only completely satisfactory basis for their family classification, the systematic position of Oliarces will not be truly solved until its immature stages have been discovered.

Adainis, P. A.

\section{References Cited}

1950. Notes on Oliarces clara Banks. Pan-Pacific Ent., 26:137-138.

BANKS, N.

1908. A new genus and species of Neuroptera. Ent. News, 19:203-204.

Brues, C. T. and A. L. Melander

1932. Classification of insects. Bull. Mus. Comp. Zool. Harvard Coll., $73: 1-672$.

Carpenter, F. M.

1940. Revision of the Neartic Hemerobiidae, Berothidae, Sisyridae, Polystoechotidae and Dilaridae. Proc. Amer. Acad. Arts Sci., 74:193-280.

GanNetT, $\mathrm{H}$.

1906. Dictionary of altitudes in the United States. U.S. Geol. Surv., Bull. 274 (Ser. F, geogr. 47) :1-1072.

KILlingJoN, F. J.

1936-37. Monograph of British Neuroptera. 2 vols. Ray Soc.

LAMEE:E, A.

1936. Précis de Zoologie, 5:25-47.

M'LACHAN, R.

1886. A new genus of Hemerobiidae, and a new genus of Perlidae.

Tilly ARD, R. J. Trans. Ent. Soc. Lond., (3) 5 (4) :353-354.

1916. Studies in Aus ralian Neuroptera. No. 4. The Families Ithonidae, Hemerobiidae, Sisyridae, Berothidae. Proc. Linn. Soc. N. S. Wales, 41:270-332.

191: Studies in Australian Neuroptera. No. 8. Revision of the Family Ithonidae. Proc. Linn. Soc. N. S. Wales, 44:414-437.

\section{Explanation of Plate 4}

Fig. 1. Terminal abdominal segments of male of Ithone fusca Newman. Drawn from specimen in M. C. Z. (Woy Woy, N. S. W., Nov. 5, 1918, R. J. T.). 1A, dorsal view; 1B, lateral view; 1C, ventral view; ap. anal plate; $8 \mathrm{~T}, 9 \mathrm{~T}, 10 \mathrm{~T}$, abdominal tergites; $8 \mathrm{~S}, 9 \mathrm{~S}$, abdominal sternites. Fig. 2. Terminal abdominal segments of male of Oliarces clara Banks. Drawn from holotype (M. C. Z.). a, anus. Other lettering as in figure 1. 

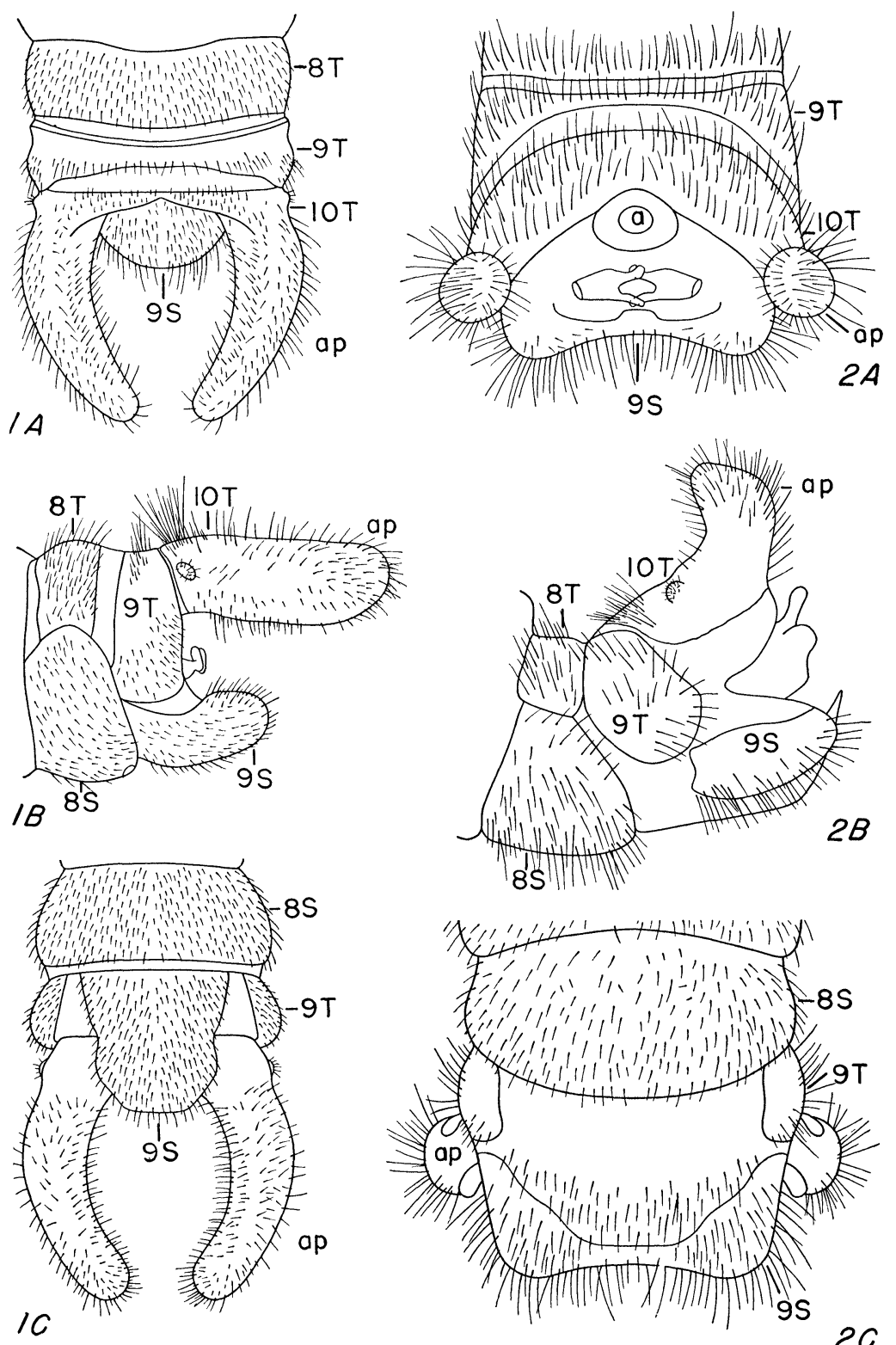

CarPenter — Oliarces 

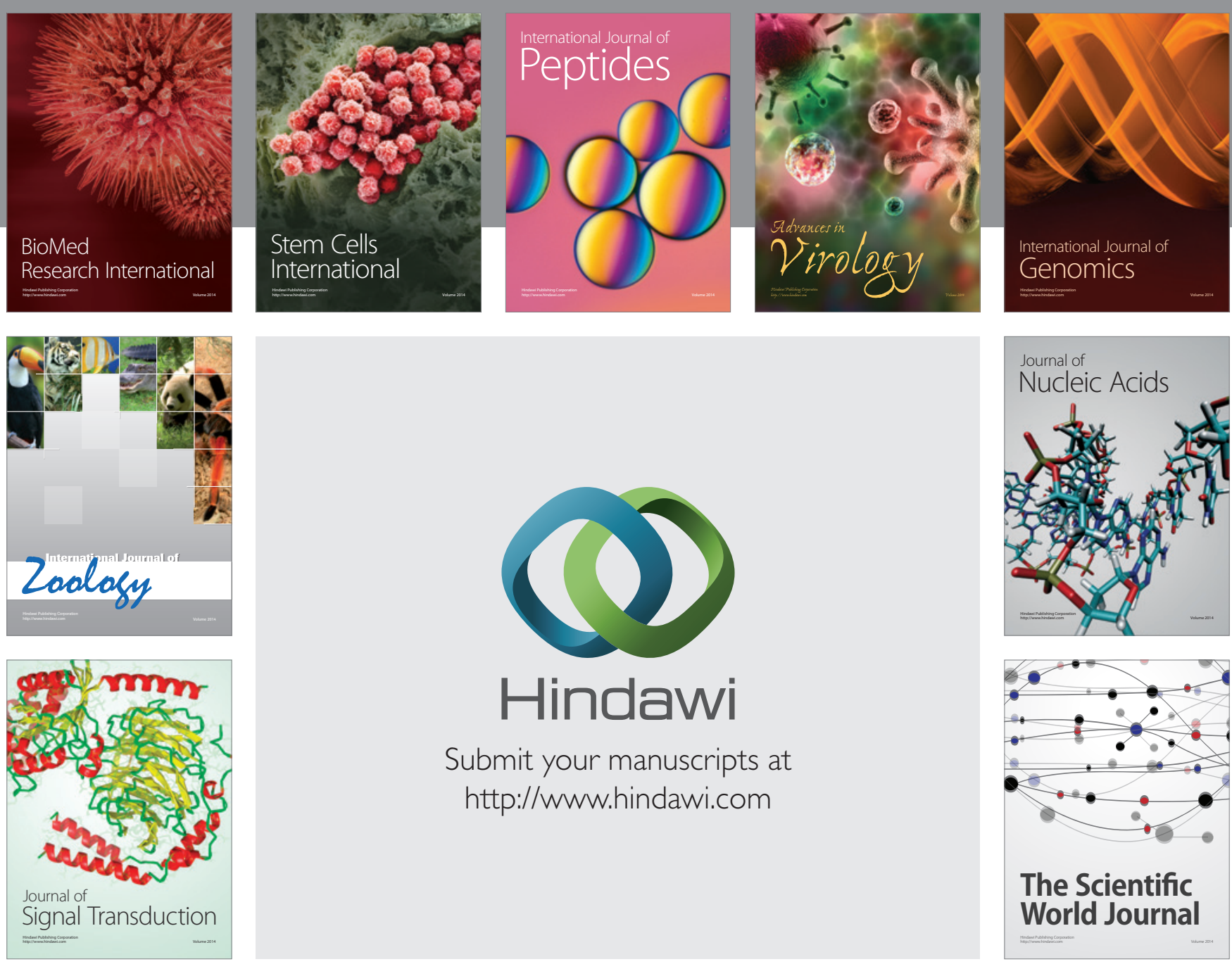

Submit your manuscripts at

http://www.hindawi.com
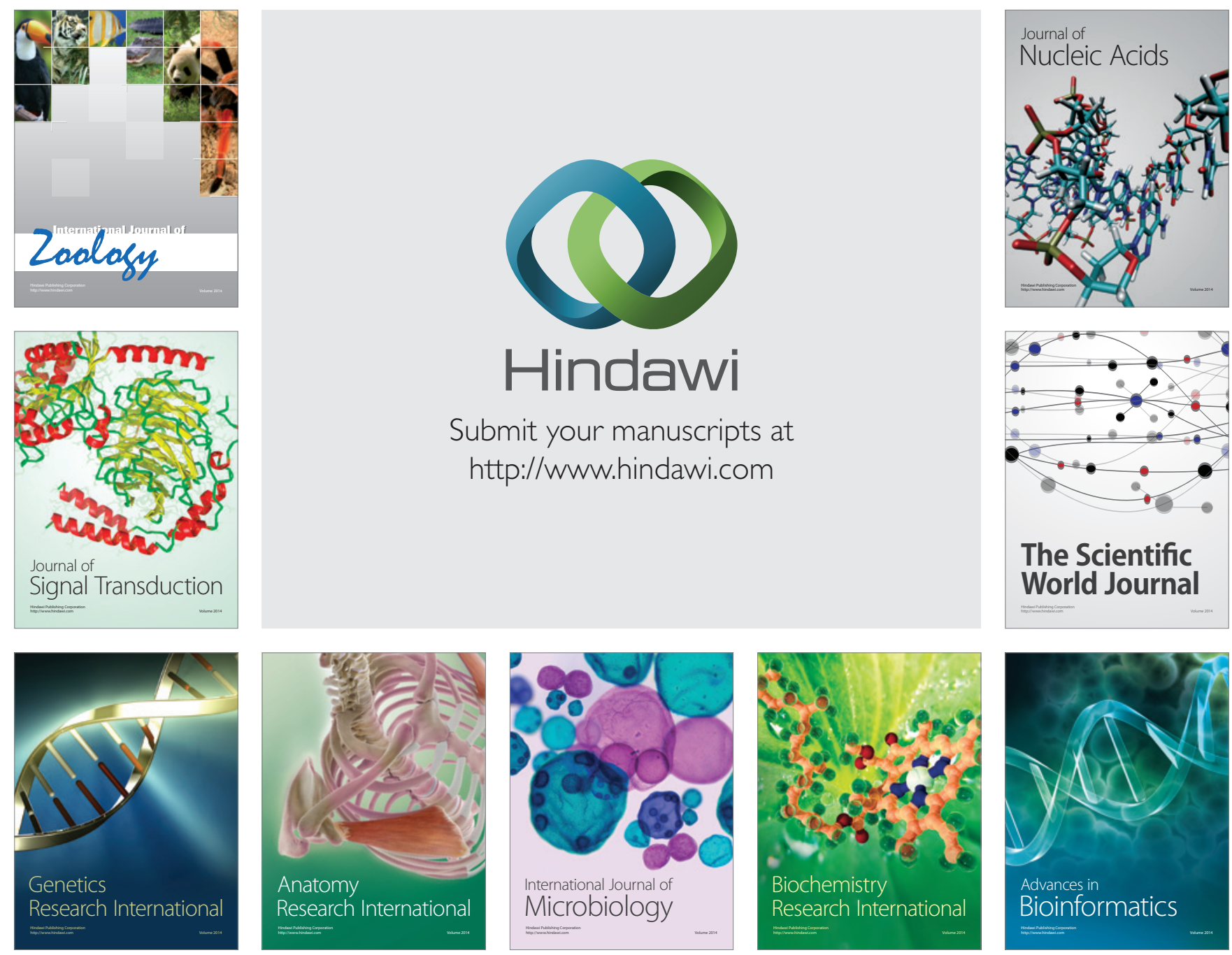

The Scientific World Journal
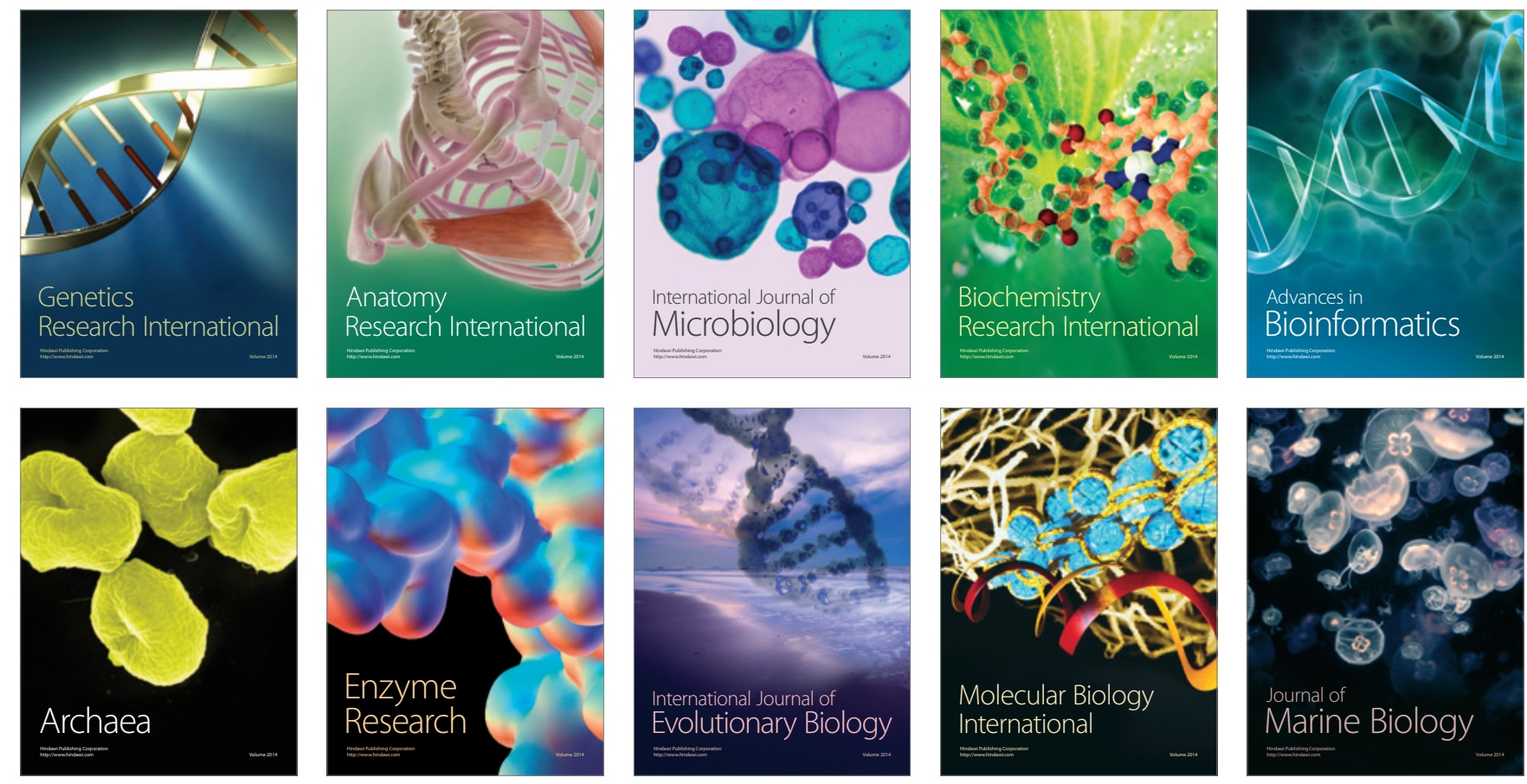